Original Research

\title{
Barriers to healthcare access for Arabic-speaking population in an English-speaking country
}

\author{
Ali A. AL-JUMAILI ID, Kawther K. AHMED ID, Dave KOCH (ID). \\ $\begin{array}{llll}\text { Received (first version): } 11-J a n-2020 & \text { Accepted: 10-May-2020 Published online: 15-May-2020 }\end{array}$
}

\begin{abstract}
Objective: To identify barriers to healthcare access, to assess the health literacy levels of the foreign-born Arabic speaking population in lowa, USA and to measure their prevalence of seeking preventive healthcare services.

Methods: A cross-sectional study of native Arabic speaking adults involved a focus group and an anonymous paper-based survey. The focus group and the Andersen Model were used to develop the survey questionnaire. The survey participants were customers at Arabic grocery stores, worshippers at the city mosque and patients at free University Clinic. Chi-square test was used to measure the relationship between the characteristics of survey participants and preventive healthcare services. Thematic analysis was used to analyze the focus group transcript.

Results: We received 196 completed surveys. Only half of the participants were considered to have good health literacy. More than one-third of the participants had no health insurance and less than half of them visit clinics regularly for preventive measures. Two participant enabling factors (health insurance and residency years) and one need factor (having chronic disease(s)) were found to significantly influence preventive physician visits.

Conclusions: This theory-based study provides a tool that can be used in different Western countries where Arabic minority lives. Both the survey and the focus group agreed that lacking health insurance is the main barrier facing their access to healthcare services. The availability of an interpreter in the hospital is essential to help those with inadequate health literacy, particularly new arriving individuals. More free healthcare settings are needed in the county to take care of the increasing number of uninsured Arabic speaking patients.
\end{abstract}

Keywords

Health Services Accessibility; Preventive Health Services; Medically Uninsured; Health Literacy; Communication Barriers; Cultural Competency; Surveys and Questionnaires; Focus Groups; United States

\section{INTRODUCTION}

The Arabic community is a growing minority in the United States. In 2017, there were approximately 3.7 million Arab Americans living in the United States. ${ }^{1}$ Arab Americans live in all 50 states with about half of them residing in California, Florida, Michigan, New Jersey, and New York. ${ }^{2}$ In the state of lowa in the Midwest, Arabs constitute about $0.15 \%$ of the total state population. ${ }^{2}$ Health data on Arab Americans are lacking mainly due to the lack of an Arab identifier in healthcare records and surveys. ${ }^{3}$ Like other minorities, the healthcare needs of Arab Americans and their access to healthcare needs more focus.

Lack of insurance subjects individuals to the economic burden of needed medical care expenses and pertains to infrequent or no regular checkups and screenings for major health problems like diabetes mellitus (DM), cardiovascular diseases, and cancer. ${ }^{4,5}$ Minorities have been reported to largely contribute to the uninsured population in the U.S. and this was attributed to low income or new arrival. ${ }^{6}$ Lack of health insurance was one of the main barriers to accessing healthcare for Latinos in South Carolina. ${ }^{7}$ and was found to correlate positively with having a regular healthcare provider and completing diagnostic tests for African Americans. ${ }^{8}$ Similarly, unaffordable healthcare

\footnotetext{
Ali Azeez AL-JUMAILI. MPH, PhD. College of Pharmacy, University of Baghdad. Baghdad (Iraq). aliazeezali-aljumaili@uiowa.edu Kawther Khalid AHMED. PhD. College of Pharmacy, University of Baghdad. Baghdad (Iraq). kawther-ahmed@uiowa.edu Dave KOCH. BS. Johnson County Public Health. lowa City, IA (United States).dkoch@co.johnson.ia.us
}

services were reported as a barrier to healthcare services by Arab Americans in Brooklyn as well as other minorities. ${ }^{7,9}$

Language is another barrier that has been reported to impact the access and quality of healthcare. ${ }^{7}$ For nonEnglish speaking individuals, language barriers can affect the frequency of visits, willingness to get healthcare and knowledge about available healthcare services. It was found that the self-rated health of Arabic-speaking immigrants was lower than that of both English-speaking Arab immigrants and U.S. born Arab Americans, suggesting language as a contributing factor to differences in health status and healthcare access. ${ }^{10}$ Several approaches have been reported to successfully bridge the gap in healthcare services for non-English speakers in the U.S. including professional translators, employment of bilingual physicians, and provision of non-English health educational materials. ${ }^{11-13}$ Several studies have demonstrated that the presence of professional interpreters or bilingual providers during physician visits for individuals with limited English proficiency had a positive impact on patient satisfaction and the outcomes of the healthcare services provided. ${ }^{14-17}$

Healthcare access was mostly studied in the term of enablers and barriers to required intervention as in the case of sickness. ${ }^{18}$ Fewer studies have explored preventive healthcare use among Arab Americans (for the purpose of this study, the term preventive healthcare includes physician visits for non-urgent needs, regular checkups/physician visit for existing health conditions, clinic visits for vaccination, and clinic visits for screening). 
Individuals usually seek healthcare services in urgent illnesses regardless of the ease of access, while non-urgent healthcare needs (such as vaccination, screening and regular check-up) can be overlooked according to the ease of access. Hence, in this study we focused on the barriers and enabling factors influencing the access to preventive healthcare services. Access to healthcare for minorities has been the focus of many studies. ${ }^{7,17,19,20}$ However, limited data is available on Arabic minority communities in given geographic parts of the U.S. including the Midwest region. This study has not only focused on barriers and enabling factors to preventive health care access, but also assessed the pattern of access to preventive healthcare among this minority in this understudied region of the United States. To the best of our knowledge, this is the first study to use survey to examine the healthcare needs of the Arabic speaking minority in the Midwest region of the United States.

The objectives of this study were to identify barriers to healthcare access, to assess health literacy level of the Arabic speaking (foreign-born) population in Johnson County, lowa, USA and to measure their prevalence of seeking preventive healthcare services.

\section{METHODS}

This cross-sectional study involved two methods: A focus group and an anonymous survey of Arabic speaking individuals in Johnson County in the state of lowa, USA. The interview guide of the focus group was developed in collaboration with Johnson County Public Health (JCPH) to assess the difficulties, concerns, and suggestions regarding healthcare access for the Arabic speaking community (Online appendix). The JCPH has experience to conduct need assessment interviews among minority communities every five years. The focus group took place at the lowa City Mosque, and the focus group team included a note taker, a translator/assistant moderator, and the group leader. It was recorded using two tape recorders.

To analyze the verbatim transcript of the focus group, we followed the six phases of thematic analysis described by Braun and Clarke which include familiarizing oneself with the focus group verbatim, generating initial codes, searching for themes, reviewing themes, defining and naming themes and producing the report. ${ }^{21}$ The coding process was conducted by three researchers and the final themes agreed on by all or at least two of three team members. To enhance the credibility and trustworthiness of the findings, peer debriefing / member checking was conducted to validate the qualitative analysis. The process of member checking to test the findings and interpretations was conducted with five of the participants.
After conducting the focus group, the authors created a survey in English based on the Andersen Model for healthcare service utilization (Figure 1 ) and employing the findings of the focus group. ${ }^{22}$ Andersen model can help to measure predisposing, enabling and need factors that influence the use of healthcare services (preventive physician visits).

The survey contained 20 questions covering predisposing items (age, gender, ethnicity, education), enabling items (health insurance, residency and health literacy), need items (presence of chronic diseases) and healthcare utilization item (frequency of physician visits), which represent the outcome variable (Online appendix). Health literacy was assessed using the Arabic version of Single Item Literacy Screener (SILS). ${ }^{23}$ The SILS has one question: "How often do you ask someone for help to read the instructions and leaflets from a doctor or pharmacy?". ${ }^{24}$ The participants were asked to choose one of the followings (5-point Likert scale): 1-never, 2-rarely, 3sometimes, 4-often, or 5-always. ${ }^{25}$

To eliminate the language barrier, the survey was translated to formal Arabic by the authors and the translation was validated by two different native Arabic scholars living in the county. The survey was pretested in pilot study with few native-Arabic speakers before administering to all participants. Two questions were revised according to the pilot study feedback. We added other answer choices. First change was conducted to question "Do you have a family member who is fluent in English helping you during physician/pharmacy visits? "when we added $4^{\text {th }}$ choice of "No need". The second revision included adding "visitor" to demographic section when we ask about the resident status. The inclusion criteria of the survey participants were being first generation Arabic immigrants, adult ( $>18$ years) and living in Johnson County. A bilingual English/Arabic researcher (AA) screened participants for eligibility. Visitors and students were also surveyed as they constitute an important component of the community due to the presence of the University of lowa that attracts a considerable number of international students and visiting scholars and their dependents (4011 international students and scholars out of 86,769 total residents). ${ }^{26,27} \mathrm{~A}$ bilingual English/Arabic researcher (AA) approached customers at Arabic grocery stores in Coralville, worshippers at the lowa City Mosque and patients at the free University Mobile Clinic and asked if they were willing to complete the survey. Subsequently, people who gave verbal consent were provided a 2-page paper survey, which the authors collected in-person. The research team distributed the paper-survey in-person and waited till participants filled it out. Only people who agreed to participate received the

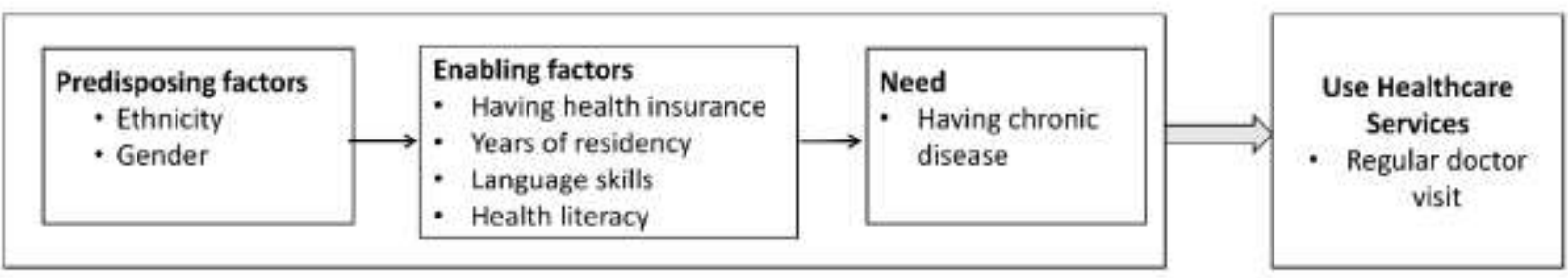

Figure 1. The Andersen model of preventive health care utilization 
survey (convenience sample). We did not measure the response rate because we were unable to count all people available at the three included settings. In general, most eligible people were cooperative and agreed to participate.

The study proposal was exempted by the University of lowa Human Subject Office/ Institutional Review Board (IRB).

\section{Quantitative Statistical Analyses}

Means, frequencies and percentages of participant characteristics were calculated. The data analyses were performed utilizing the IBM SPSS Program for Windows, version 22.0. The chi-square test was used to measure the relationship between the categorical participant factors (no health insurance, language barrier, health literacy, no barrier, chronic disease, gender, ethnicity, and residency years in the U.S.) and the outcome variable (preventive / regular physician visits). The chi-square analysis was also conducted to measure the relationships between health literacy level and both language barrier and interpreter need. The statistically significant value was $p$-value $<0.05$.

\section{RESULTS}

\section{Qualitative findings}

The focus group included seven native Arabic speaking residents who were married with children, and all had at least a college degree. The main theme of the qualitative findings of the focus group was barriers facing Arabic speaking population regarding access to healthcare services. Lack of health coverage/insurance or instability of insurance status was noted as the major barrier to healthcare access in this community and can be put into the following three subthemes. First, lack of coverage due to eligibility issues. For example, a participant (P3) in the focus group stated "concerning my family, we are six including my kids and wife. We have insurance from Medicaid for the kids, but for me and my wife, we do not have insurance". The adult parents were not eligible to be covered according to lowa Medicaid rules at the time focus group conducted. The second subtheme was lack of health insurance due to affordability. For instance, P2 mentioned "through my employment I can't afford it [health insurance], it's too high!" The third subtheme was the limited availability and accessibility of medical services for residents without health insurance. For example, P4 stated, "Regarding the free clinic, before I got my insurance, I was getting the services from there; it's a good clinic but it's a very small clinic, and the most [/biggest/] problem with that is that you can't just walk in and get services". Regardless of the cause of having no access to healthcare services, individuals might find themselves forced to use the emergency room (ER), which sends them home with overwhelming bills: "After that, we kept going to the ER and they kept sending us the bill, right now I have more than USD 250,000 [debt]" (P6).

\section{Quantitative results}

We received 196 surveys from adult native Arabic speakers who lived in Johnson County, lowa, USA during fall 2017. Participants gender and ethnicity are detailed in Table 1. The participants were all native Arabic speakers who have been residing in the U.S. for varying durations ranging from less than a year to more than 15 years (Table 1 ).

Regarding immigration status, survey participants were initially grouped into two main groups: citizens/residents and international students/visitors. Approximately $80 \%$ of the participants were citizens/permanent residents while

\begin{tabular}{|c|c|c|}
\hline Characteristics & $\begin{array}{l}\text { Number of } \\
\text { participants } \\
\text { (N) }\end{array}$ & $\%$ \\
\hline \multicolumn{3}{|l|}{ Residency status ( $\mathrm{N}=196)$} \\
\hline Citizen & 68 & 34.7 \\
\hline Permanent resident & 92 & 46.9 \\
\hline Student & 23 & 11.7 \\
\hline Visitor & 13 & 6.6 \\
\hline \multicolumn{3}{|l|}{ Gender ( $N=196)$} \\
\hline Male & 119 & 60.7 \\
\hline Female & 75 & 38.3 \\
\hline \multicolumn{3}{|l|}{ Age (years) ( $\mathrm{N}=193)$} \\
\hline $18-29$ & 33 & 16.8 \\
\hline $30-39$ & 67 & 34.2 \\
\hline $40-49$ & 51 & 26 \\
\hline $50+$ & 42 & 21.4 \\
\hline \multicolumn{3}{|l|}{ Education degree $(\mathrm{N}=194)$} \\
\hline Elementary school & 7 & 3.6 \\
\hline Middle school & 13 & 6.6 \\
\hline High school & 28 & 14.3 \\
\hline College degree & 103 & 52.6 \\
\hline Graduate degree & 43 & 21.9 \\
\hline \multicolumn{3}{|l|}{$\begin{array}{l}\text { Current or former student at a US college } \\
(\mathrm{N}=194)\end{array}$} \\
\hline Yes & 114 & 58.2 \\
\hline No & 80 & 40.8 \\
\hline \multicolumn{3}{|l|}{ Ethnicity (country of origin) ( $\mathrm{N}=195$ ) } \\
\hline Sudanese & 131 & 66.8 \\
\hline Middle East & 37 & 18.9 \\
\hline North Africa & 20 & 10.2 \\
\hline Arabic-Gulf country & 7 & 3.6 \\
\hline \multicolumn{3}{|l|}{ Residency years in the U.S. $(\mathrm{N}=196)$} \\
\hline $\begin{array}{r}\text { Less than } 1 \text { years } \\
\quad\end{array}$ & 26 & 13.3 \\
\hline $1-5$ years & 91 & 46.4 \\
\hline $6-10$ years & 28 & 14.3 \\
\hline $11-15$ years & 19 & 9.7 \\
\hline More than 15 years & 32 & 16.3 \\
\hline \multicolumn{3}{|l|}{$\begin{array}{l}\text { Single Item (SILS) health literacy Screener: } \\
\text { Need help to read physician/pharmacist } \\
\text { instructions ( } N=196 \text { ) }\end{array}$} \\
\hline $\begin{array}{lll} & \text { Always }\end{array}$ & 24 & 12.2 \\
\hline Often & 24 & 12.2 \\
\hline Sometimes & 45 & 23 \\
\hline Rarely & 21 & 10.7 \\
\hline Never & 82 & 41.8 \\
\hline \multicolumn{3}{|l|}{$\begin{array}{l}\text { Need an interpreter during hospital/clinic } \\
\text { visits }(\mathrm{N}=196)\end{array}$} \\
\hline $\begin{array}{lll}\text { Always } & \end{array}$ & 46 & 23.5 \\
\hline Sometimes & 57 & 29.1 \\
\hline Never & 93 & 47.4 \\
\hline \multicolumn{3}{|c|}{$\begin{array}{l}\text { Citizens/permanent residents }=160 \text { and students/visitors }=36 . \\
\text { Participants of Sudan ethnicity were separated from North Africa } \\
\text { as Sudanese represent the largest component of the Arabic } \\
\text { speaking minority in the study area. } 131 \text { are Sudanese, } 23 \text { from } \\
\text { Middle East and } 17 \text { of them are Iraqis and } 6 \text { from Levant. All the } \\
14 \text { students from Middle East are Iraqis. North African Arabic } \\
\text { countries include Egypt, Libya, Algeria, Tunisia \& Morocco; Middle } \\
\text { Eastern Arabic countries include Iraq, Jordan, Syria and Lebanon; } \\
\text { Gulf-Arabic countries include Saudi Arabia and United Arab } \\
\text { Emirates. }\end{array}$} \\
\hline
\end{tabular}




\begin{tabular}{|c|c|c|}
\hline Characteristics & Num. & $\%$ \\
\hline \multicolumn{3}{|l|}{ Having Health insurance $(\mathrm{N}=196)$} \\
\hline No & 74 & 37.7 \\
\hline \multicolumn{3}{|l|}{ High Co-payment ( $\mathrm{N}=196)$} \\
\hline 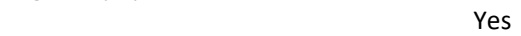 & 25 & 12.8 \\
\hline \multicolumn{3}{|l|}{ Having language barrier $(\mathrm{N}=196)$} \\
\hline Yes & 31 & 15.8 \\
\hline \multicolumn{3}{|l|}{$\begin{array}{l}\text { Having barrier(s) to healthcare access } \\
(\mathrm{N}=196)\end{array}$} \\
\hline Yes & 84 & 42.9 \\
\hline \multicolumn{3}{|l|}{$\begin{array}{l}\text { Have a family member helps in } \\
\text { interpretation during physician/ pharmacy } \\
\text { visits }(\mathrm{N}=196)\end{array}$} \\
\hline No & 76 & 38.8 \\
\hline Sometimes & 25 & 12.8 \\
\hline Yes & 48 & 24.5 \\
\hline No need & 47 & 24 \\
\hline \multicolumn{3}{|l|}{$\begin{array}{l}\text { *Health Insurance type ( } \mathrm{N}=122) \text { : Choose all } \\
\text { that apply }\end{array}$} \\
\hline Medicaid & 52 & 26.5 \\
\hline Employer/University & 47 & 24 \\
\hline Private & 15 & 7.7 \\
\hline Medicare & 8 & 4.1 \\
\hline \multicolumn{3}{|l|}{ Visit doctor/clinic $(\mathrm{N}=196)$} \\
\hline At Regular basis/For Preventive measures & 93 & 47.4 \\
\hline When very ill/ To get prescription & 103 & 52.6 \\
\hline \multicolumn{3}{|l|}{ **Having chronic disease(s) } \\
\hline 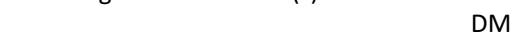 & 22 & 11.2 \\
\hline Hypertension & 30 & 15.3 \\
\hline Heart Disease(s) & 7 & 3.6 \\
\hline Asthma & 11 & 5.6 \\
\hline Arthritis & 19 & 9.7 \\
\hline No chronic disease & 132 & 67.3 \\
\hline \multicolumn{3}{|c|}{$\begin{array}{l}\text { * One resident was dual Medicaid and Medicare insured, } \\
\text { while other participant did not specify his type of health } \\
\text { insurance. }\end{array}$} \\
\hline $\begin{array}{l}{ }^{* *} \mathrm{~N}=122 \text { because several participants had } \\
\text { diseases. }\end{array}$ & ultiple & hronic \\
\hline
\end{tabular}

the remaining $20 \%$ were students and visitors temporarily residing in the United States (Table 1). Upon initial chisquare analysis, no significant differences were found in terms of barriers to healthcare service use reported by participants in the two groups (citizens/residents and international students/visitors). Hence, for subsequent chisquare tests, all participants were grouped together.

Looking at the pattern of physicians visits, about $70 \%$ of participants reported visiting the physician to seek treatment when they are very ill or to request a prescribed medication from their physician, while preventive and regular physician visits were reported by only half $(52.6 \%)$ the participants (Table 2). Chi-square analyses showed that having any barrier significantly influenced regular physician visits by participants. Barriers surveyed and reported in this study were lack of health insurance, co-payment, and language (Table 2 ). Approximately $43 \%$ of all participants reported having one or more barriers (no health insurance, language barrier and/or high co-payment) to using healthcare services (Table 2). There was a significant $(p<0.05)$ association between the presence of barrier(s) to healthcare and the use of preventive healthcare (Table 3 ) such that participants experiencing any barriers had fewer regular physician clinic visits than those without barriers. Looking more specifically at select barriers/factors, three participant factors significantly influenced the regular visit

\begin{tabular}{|c|c|c|}
\hline Factors (total num.) & $\begin{array}{c}\text { Regular } \\
\text { visit } \\
\mathrm{n}(\%) \\
\end{array}$ & $\begin{array}{c}\text { Chi-square } \\
\text { p-value }\end{array}$ \\
\hline No health insurance & $\begin{array}{l}79(64.8) \\
14(18.9)\end{array}$ & 0.0001 \\
\hline Language barrier & $\begin{array}{l}79(47.9) \\
14(45.2) \\
\end{array}$ & 0.781 \\
\hline $\begin{array}{r}\text { Male (119) } \\
\text { Female (75) }\end{array}$ & $\begin{array}{l}54(45.4) \\
38(50.7)\end{array}$ & 0.473 \\
\hline *Residency Years & $\begin{array}{l}42(35.9) \\
51(64.6)\end{array}$ & 0.0001 \\
\hline $\begin{array}{r}* * \text { Others }(63) \\
\text { Sudanese (133) }\end{array}$ & $\begin{array}{l}31(49.2) \\
62(46.6)\end{array}$ & 0.735 \\
\hline $\begin{array}{r}\text { With (64) } \\
\text { Without (132) }\end{array}$ & $\begin{array}{l}40(62.5) \\
53(40.2)\end{array}$ & 0.003 \\
\hline $\begin{array}{r}* * * \text { SILS (health literacy) } \\
\text { Inadequate (93) } \\
\text { Adequate (103) }\end{array}$ & $\begin{array}{l}42(45.2) \\
51(49.5)\end{array}$ & 0.542 \\
\hline \multicolumn{3}{|c|}{$\begin{array}{l}\text { *Years of residency in the US: } 1=5 \text { years or less, } 2=\text { more than } 5 \\
\text { years. } \\
\text { **Others: North African Arabic, Middle-Eastern Arabic, Yemeni } \\
\text { and Gulf-Arabic participants. } \\
\text { ***Adequate health literacy=those answered "never or rarely" } \\
\text { to the SILS question, while inadequate health literacy=those }\end{array}$} \\
\hline
\end{tabular}

of physician clinic and these were having health insurance (enabling factor), having chronic disease(s) (need factor), and the number of residency years (5 years or less vs more than 5 years) in the U.S. (enabling factor) (Table 3).

Regarding health insurance, which is an enabling factor in the Anderson model, more than one-third (38\%) of the participants had no health insurance (Table 2). All the 23 participating international students had health insurance. The majority of participating permanent residents (61.5\%) had no health insurance while a small percentage (15.3\%) of the citizens was without health insurance. Most of the insured participants had health insurance provided through an employer or the university or through Medicaid and Medicare while only less than $10 \%$ of the insured participants had to pay for private health insurance (Table 2). There was significant positive association between seeking preventive/regular healthcare services and having health insurance. The majority (64.8\%) of participants with health insurance visit the physician clinic seeking regular/preventive healthcare services, while most participants without health insurance $(81.1 \%)$ do not visit the physician clinic for regular/preventive measures (Table 2).

The second factor with a significant positive association with preventive physician clinic visit was experiencing one or more chronic disease(s). About one-third (32.7\%) of the participants had one or more chronic disease(s) such as diabetes mellitus (DM), hypertension, heart disease, asthma, or arthritis with the most common diseases being hypertension (15.3\%) and DM (11.2\%) (Table 2). Approximately two-thirds of participants with chronic diseases reported regularly/preventively visiting the physician clinic compared to only one-third of those 
without chronic disease performing such regular/preventive visits (Table 3). The third and last factor significantly affecting the use of regular/preventive physician visits was participant's residency period. Participants less than five years of residency had significantly less regular physician clinic visits than those with more than five years of residency in the States.

Other barriers/factors examined in this study did not have significant association with preventive physician visits. For example, high co-payment of healthcare services for insured individuals was reported as a barrier by only about $15 \%$ of insured participants.

We measured three related factors: Language barrier, interpreter need, and health literacy level. Additionally, the survey asked about the availability of the hospital interpreter and preferences of using Arabic speaking providers. Regarding the provider preference, about $80 \%$ of participants had no preference for Arabic speaking providers. While around $35 \%$ of participants reported the constant availability of interpreters at the hospital/clinic, approximately half of total participants reported not needing/using the service. Approximately $16 \%$ of participants perceived having a language barrier and the remaining $84 \%$ did not report language as a barrier to healthcare (Table 2). Additionally, the perception of language as a barrier to healthcare was found to associate positively with the level of education of the participant such that those with college education and higher have no issues with comfortably communicating in English (Table 1). On the other hand, the Single Item health Literacy Screener (SILS) test revealed that only half of the participants were considered having good health literacy $(52.6 \%$ reported never/rarely needing help read physician/pharmacist instructions) (Table 1). Finally, neither health literacy level nor language barrier had significant relationship with the outcome variable (regular/preventive physician visits) (Table 3).

The chi-square analysis showed that there were significant $(p<0.05)$ relationships between health literacy level and both language barrier and interpreter need (Table 4). To elaborate, almost all participants with limited English proficiency (30/31) were also specified as having inadequate health literacy. On the other hand, more than one-third $(63 / 165)$ of the participants who reported having no language barrier were designated as having inadequate health literacy according to SILS results (answered sometimes, often or always need help in understanding health-related materials). Considering the association between using an interpreter service and health literacy, we found that $81.6 \%(84 / 103)$ of those reported needing an interpreter were considered to have low health literacy and the remaining $18.4 \%(19 / 103)$ of those who needed an interpreter were considered to have good health literacy (Table 4).

To further explore the association of health literacy level (SILS) with the health insurance status, we did Chi-square test which showed that percentage of people having adequate health literacy was significantly higher among people with health insurance compared to people without health insurance. We also conducted Chi-square test to measure association between the residency years $(<5$ vs $5+$

\begin{tabular}{|c|c|c|}
\hline Variable (total num.) & $\begin{array}{c}\text { Adequate SILS } \\
\text { n (\%) }\end{array}$ & $\begin{array}{c}\text { Chi-square } \\
\text { p-value }\end{array}$ \\
\hline $\begin{array}{rr}\text { Interpreter need } & \\
& \text { Never (93) } \\
\text { Sometimes/Always (103) } \\
\end{array}$ & $\begin{array}{l}84(90.3) \\
19(18.4) \\
\end{array}$ & $0.0001^{*}$ \\
\hline $\begin{array}{ll}\text { Language barrier } & \\
& \text { No (165) } \\
& \text { Yes (31) } \\
\end{array}$ & $\begin{array}{c}102(61.8) \\
1(3.2)\end{array}$ & $0.0001^{*}$ \\
\hline $\begin{array}{rr}\text { Health insurance } & \\
& \text { Yes (123) } \\
& \text { No (73) } \\
\end{array}$ & $\begin{array}{l}45(36.6) \\
48(65.8) \\
\end{array}$ & $0.0001^{*}$ \\
\hline Years in the US & $\begin{array}{c}84(51.2) \\
9(28.1)\end{array}$ & $0.017^{*}$ \\
\hline
\end{tabular}

years) and the health literacy level (SILS). We found a significant association which means people who lived for five years or more in the U.S., had significantly higher level of health literacy.

Focusing only on Sudanese participants, being the largest Arabic speaking population in the study areas (67.9\%), around $70 \%$ reported having one or more barriers to health care access with $51 \%$ of those reporting health insurance as the barrier to healthcare access. Moreover, there was a significant difference between Sudanese participants compared to other Arabic ethnicities grouped in term of lack of health insurance and having a language barrier. However, the ethnicity (Sudanese vs others) had no significant relationship with seeking preventive healthcare.

In summary, these findings denote the significance of health insurance and years of residency as enabling factors and existence of chronic disease as a need factor for seeking preventive/regular physician visits. However, health literacy, language barriers, gender and ethnicity had no significant association with performing preventive physician visits (Table 3).

\section{DISCUSSION}

In this study, we investigated barriers to receive preventive healthcare services and assessed health literacy level of the Arabic speaking community in select parts of Johnson County in the state of lowa. The study area was chosen to focus on the overlooked Arabic speaking minority living in the Midwest. This is because most studies examining Arabic speaking minority were conducted in states where the majority of the Arabic speaking minority is residing. ${ }^{9,10}$ Additionally, our unique approach in this study involved using a focus group and conducting a short paper survey. The Arabic version of the survey can be used as a tool for future studies conducted in any country containing Arabic minority.

Access to healthcare services is governed by many factors, mainly having health insurance. ${ }^{8,18}$ In cases of regular physician visits, lack of health insurance and subsequent service costs can lead to patients abandoning required visits normally scheduled for treatment follow-up, annual 
checkups, screening for certain diseases and simply followup on an existing condition.

The focus group in our study pointed out lack of health insurance as the main barrier to healthcare access. The focus group also noted that years of residency are important to receive governmental health insurance (Medicaid) and subsequently seeking preventive care. These conclusions were confirmed quantitatively and specifically in the context of preventive healthcare where chi-square analyses of the survey results showed three factors significantly influencing the outcome of the Anderson Model (preventive/ regular physician visit): Two enabling factors (health insurance, and residency years in the U.S.) and one need factor (having chronic disease(s))(Table 3 ). Because of these factors, only $52.6 \%$ of the participants visit clinic regularly and for preventive measures. According to the chi-square analysis of the survey answers, lack of health insurance had significant negative association with regular physician visits. There were $64.8 \%$ participants from those who had health insurance were visiting physician clinic regularly/for preventive measures, while only $18.9 \%$ of those who did not have health insurance were visiting physician regularly/ for preventive measures (about 3.5 to 1 ratio) (Table 3). These findings agree with previous reports on health insurance being the main barrier to general healthcare access regardless of citizenship, immigration status and ethnicity in the United States. ${ }^{4,28}$

First generation minorities might be facing more barriers to healthcare services than later generations possibly due to difficulties in communications and short residence time in the U.S. for newly arriving immigrants. Indeed, statistical analysis showed that participants with residency of five years or less had significantly fewer regular visits to clinics than those with more than five years residency in the U.S. which comes in agreement with focus group findings. These finding might be explained by the fact that new immigrants will have to wait for five years to be U.S. citizens before they are eligible for Medicaid according to the lowa Department of Human Services (DHS). During this period, individuals would mostly stay without insurance as they cannot afford private insurance. Even though children and pregnant women can receive free basic health needs (vaccination, dental, healthy foods and nutrition) from the County Public Health Department through the Women, Infants \& Children (WIC) program these services do not eliminate the need for health insurance to seek preventive healthcare. ${ }^{29}$

While in our survey sample, Sudan ethnicity was the main component (about two thirds), both predisposing factors (ethnicity and gender) had no significant relationship with the outcome variable (regular physician visit). This is worth mentioning as Sudanese were the main contributors to the uninsured participants with $51 \%$ of Sudanese uninsured compared to only $9.5 \%$ of all other participants being uninsured. This difference in the insurance status based on ethnicity might be due to differences in residency status where the majority of Sudanese were permanent residents/citizens while international students were mainly from all other ethnicities and they had to have health insurance as per university regulations.
The other modulating factor for preventive healthcare seeking is the need factor represented in this study by existence of chronic disease(s). Experiencing chronic disease(s) had a significant positive association with preventive clinic visits. This is an expected finding since those patients need regular follow-up visits to treat complications, conduct tests and receive prescribed medications. These results come in agreement with previously reported positive association between the existence of chronic disease and receiving recommended regular healthcare services. ${ }^{30,31}$

Another commonly reported barrier to healthcare access for non-English speaking minorities in the U.S. is language. ${ }^{19}$ Notably, language barrier did not have any significant relationship with preventive physician visits in this study (Table 3). It is important to note that English proficiency does not reflect health literacy where individuals can communicate efficiently and still need help reading medical materials. This is well seen in our study where more than one-third of participants who reported having no language barrier were designated as having inadequate health literacy according to SILS results. However, almost all participants with limited English proficiency were designated as having inadequate health literacy (Table 4). These results agree with previously reported findings of inadequate health literacy among limited English proficiency individuals. ${ }^{32,33}$

In our study, neither language nor health literacy had significant impact on acquiring preventive care (Table 3 ). This is possibly due to the elimination of language gap through the availability of professional interpreter service at the healthcare centers. Our study showed that hospital interpreter service is highly used especially by participants with inadequate health literacy $(90 \%)$ and even by some participants with adequate health literacy (18.4\%). These findings highlight the importance of implementing professional interpreter services and comes in agreement with previously reported findings of a significant increase in patient satisfaction and healthcare delivery for both preventive and clinical services after the implementation of a professional interpreter service compared to a control group for Portuguese and Spanish speaking population. ${ }^{14,15}$ Additionally, health literacy level was significantly associated with the status of being insured and being residents for five years or more. These findings might be explained because people having health insurance were residents for longer time in the U.S. and this longer period of residency contributed to their improved health literacy level.

We also conducted chi-square test to measure association between the residency years ( $<5$ vs $5 \leq$ years) and the health literacy level (SILS). We found a significant association which means people who lived for five years or more in the U.S., they have significantly higher percentage of those having adequate health literacy

This study had some limitations. Mainly, it was conducted in one county which may limit the generalizability of our findings. However, this county has different cities which contain a good number of Arabic speaking residents. One focus group with a limited number of participants was the other limitation. However, we used the verbatim of the 
focus group to generate the survey items and generalize the healthcare barrier findings among this minority. Lastly, some surveys had missing answers.

\section{CONCLUSIONS}

This theory-based study provides a tool that can be used in different Western countries where Arabic minority lives. Andersen model helped us to identify factors associated with preventive/regular physician visits among native Arabic speaking population in Johnson County. Two enabling factors (health insurance, and residency years in the U.S.) and one need factor (having chronic disease(s)) significantly influence preventive/regular physician visits. Both the survey and the focus group results agreed that lacking health insurance is the main barrier to accessing healthcare services. The availability of an interpreter in the hospital is essential to help those with inadequate health literacy, particularly new arriving individuals.

\section{ACKNOWLEDGEMENTS}

The authors would like to thank Dr. Arwa Owais (the University of lowa College of Dentistry) and Aparna Ingleshwar for their help in conducting the focus group. We also appreciate the useful discussions with Jeani Kimbel (the University of lowa, College of Public Health) throughout the survey development.

\section{CONFLICT OF INTEREST}

The authors declare no conflict of interest.

\section{FUNDING}

No funding was received.

\section{References}

1. Arab American Institute. National Arab American Demographics. Available at: https://www.aaiusa.org/demographics (accessed Apr 7, 2018)

2. Patricia de la Cruz G, Brittingham A. The arab population: 2000. Washington: U.S.Department of Commerce EaSA; 2003.

3. Abuelezam N N, El-Sayed A M, Galea S. Arab american health in a racially charged U.S. Am J Prev Med. 2017;52(6):810-812. https://doi.org/10.1016/j.amepre.2017.02.021

4. Brown ER. Access to health insurance in the united states. Med Care Rev. 1989;46(4):349-385. https://doi.org/10.1177/107755878904600402

5. Ayanian JZ, Weissman JS, Schneider EC, Ginsburg JA, Zaslavsky AM. Unmet health needs of uninsured adults in the united states. JAMA. 2000;284(16):2061-2069. https://doi.org/10.1001/jama.284.16.2061

6. Gareld R, Majerol M, Damico A, Foutz J. The uninsured: A primer. Key facts about health insurance and the uninsured in the era of health reform. Washington: Kaiser Family Foundation; 2015.

7. Luque JS, Soulen G, Davila CB, Cartmell K. Access to health care for uninsured latina immigrants in south carolina. BMC Health Serv Res. 2018;18(1):310. https://doi.org/10.1186/s12913-018-3138-2

8. Smith D A, Akira A, Hudson K, Hudson A, Hudson M, Mitchell M, Crook. The effect of health insurance coverage and the doctor-patient relationship on health care utilization in high poverty neighborhoods. Prev Med Rep. 2017;7:158-161. https://doi.org/10.1016/i.pmedr.2017.06.002

9. Sarsour L, Tong V S, Jaber O, Talbi M, Julliard K. Health assessment of the arab american community in southwest brooklyn. J Community Health. 2010;35(6):653-659. https://doi.org/10.1007/s10900-010-9260-7

10. Abdulrahim S, Baker W. Differences in self-rated health by immigrant status and language preference among arab americans in the detroit metropolitan area. Soc Sci Med. 2009;68(12):2097-2103. https://doi.org/10.1016/..socscimed.2009.04.017

11. Tocher T M, Larson E. Quality of diabetes care for non-english-speaking patients. A comparative study. West J Med. 1998;168(6):504-511.

12. Manson $A$. Language concordance as a determinant of patient compliance and emergency room use in patients with asthma. Med Care. 1988;26(12):1119-1128. https://doi.org/10.1097/00005650-198812000-00003

13. Taira DA. Improving the health and health care of non-english-speaking patients. J Gen Intern Med. 1999;14(5):322-323. https://doi.org/10.1046/j.1525-1497.1999.00345.x

14. Jacobs EA, Lauderdale DS, Meltzer D, Shorey JM, Levinson W, Thisted RA. Impact of interpreter services on delivery of health care to limited-english-proficient patients. J Gen Intern Med. 2001;16(7):468-474. https://doi.org/10.1046/j.15251497.2001.016007468.x

15. Jacobs EA, Sadowski LS, Rathouz PJ. The impact of an enhanced interpreter service intervention on hospital costs and patient satisfaction. J Gen Intern Med. 2007;22(Suppl 2):306-311. https://doi.org/10.1007/s11606-007-0357-3

16. Flores $\mathrm{G}$. The impact of medical interpreter services on the quality of health care: A systematic review. Med Care Res Rev. 2005;62(3):255-299. https://doi.org/10.1177/1077558705275416

17. Green AR, Ngo-Metzger Q, Legedza AT, Massagli MP, Phillips RS, lezzoni LI. Interpreter services, language concordance, and health care quality: Experiences of asian americans with limited english proficiency. J Gen Intern Med. 2005;20(11):1050-1056. https://doi.org/10.1111/j.1525-1497.2005.0223.x

18. Alzubaidi H, Mc Namara K, Browning C, Marriott J. Barriers and enablers to healthcare access and use among arabicspeaking and caucasian english-speaking patients with type 2 diabetes mellitus: A qualitative comparative study. BMJ Open. 2015;5(11):e008687. https://doi.org/10.1136/bmjopen-2015-008687

19. Flores G. Language barriers to health care in the united states. N Engl J Med. 2006;355(3):229-231. https://doi.org/10.1056/NEJMp058316 
20. Hacker K, Anies M, Folb BL, Zallman L. Barriers to health care for undocumented immigrants: A literature review. Risk Manag Healthc Policy. 2015;8:175-183. https://doi.org/10.2147/RMHP.S70173

21. Braun V, Clarke V. Using thematic analysis in psychology. Qualitative Res Psychol. 2006;3(2):77-101.

22. Andersen R M. Revisiting the behavioral model and access to medical care: Does it matter? J Health Soc Behav. 1995;36(1):1-10.

23. Al-Jumaili A A, Al-Rekabi M D, Sorofman B. Evaluation of instruments to assess health literacy in arabic language among Iraqis. Res Social Adm Pharm. 2015;11(6):803-813. https://doi.org/10.1016/j.sapharm.2015.02.002

24. Morris NS, MacLean CD, Chew LD, Littenberg B. The single item literacy screener: Evaluation of a brief instrument to identify limited reading ability. BMC Fam Pract. 2006;7:21. https://doi.org/10.1186/1471-2296-7-21

25. Alkhaldi TM, Al-Jumaili AA, Alnemer KA, Alharbi K, Al-Akeel ES, Alharbi MM, Alshabanah O, Juwair AB, Khoja A. Measuring the health literacy level of arabic speaking population in saudi arabia using translated health literacy instruments. Pharm Pract (Granada). 2018;16(3):1223. https://doi.org/10.18549/PharmPract.2018.03.1223

26. The university of iowa international student and scholar services. https://international.uiowa.edu/isss (accessed Apr 7 , 2018).

27. United states census bureau. https://census.gov/en.html (accessed Apr 7, 2018).

28. Hoffman C, Paradise J. Health insurance and access to health care in the united states. Ann N Y Acad Sci. 2008;1136:149-160. https://doi.org/10.1196/annals.1425.007

29. lowa department of public health. http://idph.iowa.gov/ (accessed Jan 8, 2018).

30. Ornstein SM, Jenkins RG, Litvin CB, Wessell AM, Nietert PJ. Preventive services delivery in patients with chronic illnesses: Parallel opportunities rather than competing obligations. Ann Fam Med. 2013;11(4):344-349. https://doi.org/10.1370/afm.1502

31. Culica D, Rohrer J, Ward M, Hilsenrath P, Pomrehn P. Medical checkups: Who does not get them? Am J Public Health. 2002;92(1):88-91. https://doi.org/10.2105/ajph.92.1.88

32. Sentell T, Braun K L. Low health literacy, limited english proficiency, and health status in asians, latinos, and other racial/ethnic groups in california. J Health Commun. 2012;17(Suppl 3):82-99. https://doi.org/10.1080/10810730.2012.712621

33. Chen X, Goodson P, Acosta S, Barry AE, McKyer LE. Assessing health literacy among chinese speakers in the u.S. With limited english proficiency. Health Lit Res Pract. 2018;2(2):e94-e106. https://doi.org/10.3928/24748307-20180405-01 